\title{
Hydroxyapatite Nanoparticles as Injectable Bone Substitute Material in a Vertical Bone Augmentation Model
}

\author{
AOI KANEKO ${ }^{1}$, ERIKO MARUKAWA ${ }^{2}$ and HIROYUKI HARADA ${ }^{1}$ \\ ${ }^{1}$ Oral and Maxillofacial Surgery, Graduate School of Medical and Dental Sciences, \\ Tokyo Medical and Dental University, Tokyo, Japan; \\ ${ }^{2}$ Maxillofacial Surgery, Graduate School of Medical and Dental Sciences, \\ Tokyo Medical and Dental University, Tokyo, Japan
}

\begin{abstract}
Abstract. Aim: The aim of this in vivo study was to evaluate the utility of bone graft gel containing hydroxyapatite nanoparticles in promoting bone regeneration in a mouse model of vertical bone augmentation. Materials and Methods: Gel implants with high and low viscosity were compared for their bone regenerating ability. Bone formation at 12 weeks and material reactions were observed radiographically and histologically. Results: Radiological analysis showed that most bone augmentation area in the graft material occurred in the fourth week after surgery regardless of the viscosity of the gel, and then gradually decreased. The volume of bone augmentation area was greater in the high-viscosity implant group than in the lowviscosity implant group at all time points, the difference was statistically significant at 8 and 12 weeks. Histological evaluation indicated that the new bone area was significantly smaller in the high-viscosity implant group. Conclusion: Gelatinous graft materials containing hydroxyapatite nanoparticles were confirmed to be useful in vertical bone augmentation.
\end{abstract}

Graft materials used for formation of bone tissue in dentistry include autologous bone, allogeneic bone, xenograft tissue, and artificial bone (1-5). Although many approved bone substitute materials are granular, problems remain concerning operability and dissemination to surrounding tissues. There are several clinical reports on the use of granular

This article is freely accessible online.

Correspondence to: Dr. Eriko Marukawa, 1-5-45 Yushima, Bunkyoku, Tokyo 113-8549, Japan. Tel: +81 358035500, Fax: +81 358030198, e-mail: eriko.m.osur@tmd.ac.jp

Key Words: Hydroxyapatite nanoparticles, injectable bone substitute, biodegradable materials, vertical bone augmentation, in vivo study. hydroxyapatite (HA) for filling of bone defects and creation of the residual ridge (6-11). However, it is as difficult for cells to invade this material as it is for them to infiltrate many of the block and paste-formulation bone filling materials; therefore, these materials persist for a long time, putting patients at increased risk of secondary infection $(12,13)$. However, paste and other gelatinous bone-filling materials can easily be used to fill defects and have good operability, hence they also allow for soft-tissue augmentation to be performed simultaneously. Therefore, much research effort has been focused on development of paste and gelatinous bone-filling materials $(14,15)$.

Although HA has been used for many years as a nonabsorbable biocompatible bone substitute, more recently the focus has been on the development of absorbable bone substitutes (16-18). When the area of a bone defect is filled with HA, the cycle of bone resorption by osteoclasts and bone formation by osteoblasts resumes at the bone surface, leading to the formation of new autologous bone. The highly porous and nanometer-sized granules increase the activity of osteoblasts, resulting in more rapid proliferation, adhesion, and differentiation of bone cells (19). However, it has been reported that the high porosity and small size of these HA granules interferes with resorption of the graft and ingrowth of bone (20) and that this problem can be overcome by use of a porous HA/collagen composite containing calcined HA nanoparticles that are completely absorbed and replaced by bone $(17,18)$.

HA has been used in regeneration of soft tissue in the field of otolaryngology, such as in vocal fold augmentation for vocal fold paralysis (21-24). The product used in the studies reported to date was Radiesse ${ }^{\circledR}$ injectable implant (CaHA; Merz Pharmaceuticals GmbH, Frankfurt, Germany) (24) a whitish paste formulation that can be used in either the clinic or operating room. However, this product is extremely viscous (similarly to Teflon but less dense) and lasts 3-6 months, it has been observed experimentally to not be resorbed after 1 year (24). 
Research attention is now becoming increasingly focused on HA nanoparticles, which are smaller than HA microparticles. When the size of a particle is changed from microscale to nanoscale, its solubility in water and ethanol increases (25). Nano-HA filler materials have been used for vascularization and regeneration of soft tissue in cosmetic surgery (26) and yielded good results when used to aid regeneration of bone tissue (27-29). In the studies published thus far, HA nanoparticles have been formulated as granules, in disc form, or complexed with collagen to form a sponge. The purpose of this study was to evaluate the utility of a bone graft gel containing HA nanoparticles for bone regeneration in a mice model of vertical bone augmentation.

\section{Materials and Methods}

Preparation of bone graft materials. Two types of nano-HA gel were used, one with high viscosity (containing 33\% HA) and the other with low viscosity (containing $30 \% \mathrm{HA}$ ), as shown in Table I. Both types of nano-HA gel contained a glycerin and carboxymethylcellulose matrix that was sourced from SofSera (Tokyo, Japan). The average particle size was $40 \mathrm{~nm}$. Both types of gel were confirmed to be easily delivered via a syringe with a 25$\mathrm{G}$ needle (Figure 1). The high-viscosity implant gel was able to hold its shape after pouring and had an irregular surface (Figure 1A), whereas the low-viscosity implant gel was unable to maintain its shape because of the dissociation of $\mathrm{HA}$ and water molecules (Figure 1B). The gel of both types was coated on platinum to a thickness of $20 \mu \mathrm{m}$ to obtain conductivity and the surface roughness of gels was examined using scanning electron microscopy (S4500/EMAX-7000 ${ }^{\circledR}$; Hitachi, Ltd., Tokyo, Japan) (Figure 2).

Surgical procedures. Fourteen 10-week-old male BALB/C-Slc $\mathrm{nu} / \mathrm{nu}$ mice were acquired for use in this study. All animal procedures were performed in accordance with the guidelines of Tokyo Medical and Dental University for the care and use of laboratory animals. The study protocols were approved by the Institutional Animal Care and Use Committee of Tokyo Medical and Dental University (approval number: A2019-151A).

For each mouse, anesthesia was induced by inhalation of isoflurane. An approximately $15-\mathrm{mm}$ incision was then made in the neck region without elevation of the periosteum of the calvaria. The tip of a 25-G needle was then inserted $2 \mathrm{~mm}$ anterior to the most posterior portion of the calvaria, and $500 \mu \mathrm{l}$ of high-viscosity $(n=7)$ or low-viscosity $(n=7)$ implant gel were injected under the periosteum in the center of the calvaria (Figure 3). After implantation, the flap was repositioned and the skin incision was closed. The mice were monitored postoperatively for signs of wound dehiscence and infection. At 12 weeks after implantation, the mice were euthanized using $\mathrm{CO}_{2}$ gas. The calvarias were then resected en bloc and the segments were immediately placed in $10 \%$ formaldehyde solution.

Radiographic analysis. The bone augmentation volume was examined in vivo using micro-computed tomography (CT) at $0,4,8$, and 12 weeks after surgery. Mice were scanned using an R_mCT2 micro-CT system (Rigaku Corp., Tokyo, Japan) with a voltage of 90 $\mathrm{mV}$, current of $160 \mathrm{~mA}$, and field of view of $20.0 \mathrm{~mm}$. All mice were
Table I. Summary of the composition of the two gel materials used in this study.

\begin{tabular}{lcc}
\hline & High-viscosity gel & Low-viscosity gel \\
\hline Hydroxyapatite*, wt.\% & 33.0 & 30.0 \\
Water, wt.\% & 54.6 & 57.6 \\
Glycerin, wt.\% & 11.3 & 11.3 \\
Carboxymethyl cellulose, & 1.1 & 1.1 \\
wt.\% & & \\
\hline
\end{tabular}

$* \mathrm{Ca}_{10}\left(\mathrm{PO}_{4}\right)_{6}(\mathrm{OH})_{2}$.

anesthetized with subcutaneous injection of medetomidine hydrochloride and ketamine hydrochloride for the in vivo micro-CT scans. Changes in bone augmentation volume were evaluated at 0 , 4,8 , and 12 weeks on micro-CT images obtained from Digital Imaging and Communications in Medicine files using image processing software (ImageJ, National Institutes of Health, Bethesda, MD, USA) and compared with the values recorded immediately after surgery. Maximum bone augmentation height was measured in the same way as volume analysis using image processing software (RadiAntDICOM Viewer; Medixant, Poznan, Poland).

Histological analysis. At 12 weeks after surgery, decalcified specimens were prepared from the formalin-fixed tissue, dehydrated in ascending grades of ethanol, and embedded in methyl methacrylate blocks according to the manufacturer's instructions. Next, the blocks were sliced into thin $(30-38 \mu \mathrm{m})$ sections using a sliding microtome. The sections were then stained with hematoxylin and eosin and examined under a light microscope. The ratio of the augmentation material to the area of new bone was calculated using ImageJ software (National Institutes of Health, Bethesda, MD, USA).

Statistical analysis. All data were recorded in Microsoft Excel 2016 (Redmond, WA, USA). Radiographic evaluation of the bone augmentation volume and height, and histological analysis of the residual material and new bone were performed using $t$-test (comparison among groups) and Tukey's multiple comparison test (comparison among points). All statistical analyses were performed using SPSS for Windows (IBM Corp., Chicago, IL, USA). A $p$ value of less than 0.05 was considered statistically significant.

\section{Results}

Scanning electron microscopic images of the surface of each implant gel are shown in Figure 2. The high-viscosity implant gel had an irregular appearance, maintained its shape, and contained granules of varying size. In contrast, the low-viscosity implant gel had a more regular appearance, partially maintained its shaped but tended to flatten out, and contained granules of fairly uniform size. Both the highviscosity and low-viscosity implant gels were easily and successfully injected under the periosteum using a 25-G needle with good operability. At the time of injection, no major difference was observed between the two materials. 
A

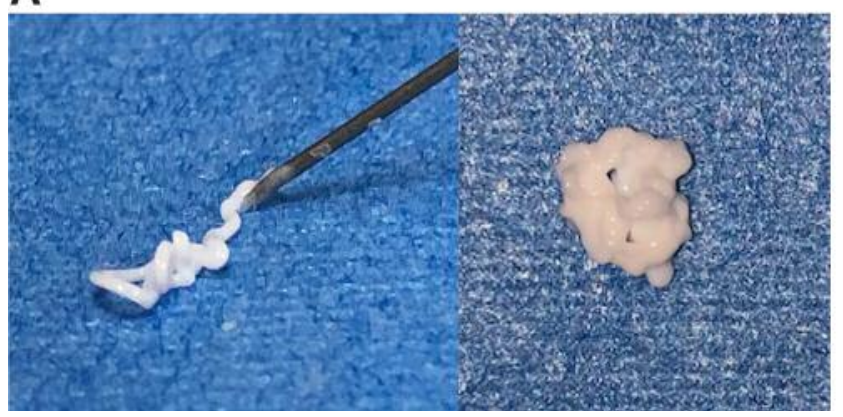

B

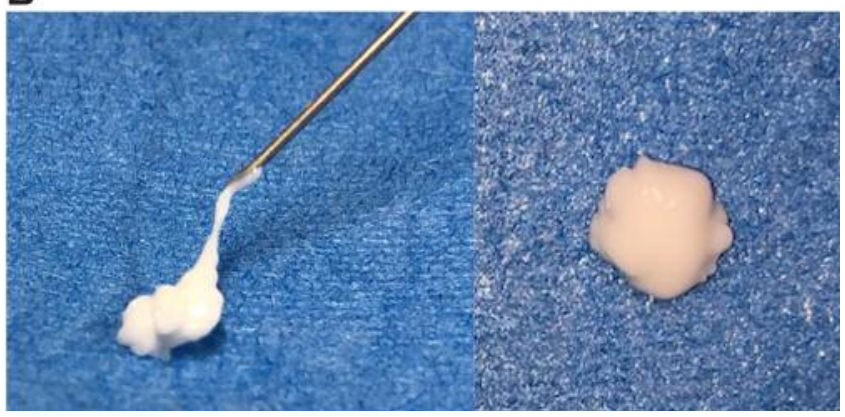

Figure 1. Gel implants containing nano-hydroxyapatite particles. A: High-viscosity gel. B: Low-viscosity gel.

A

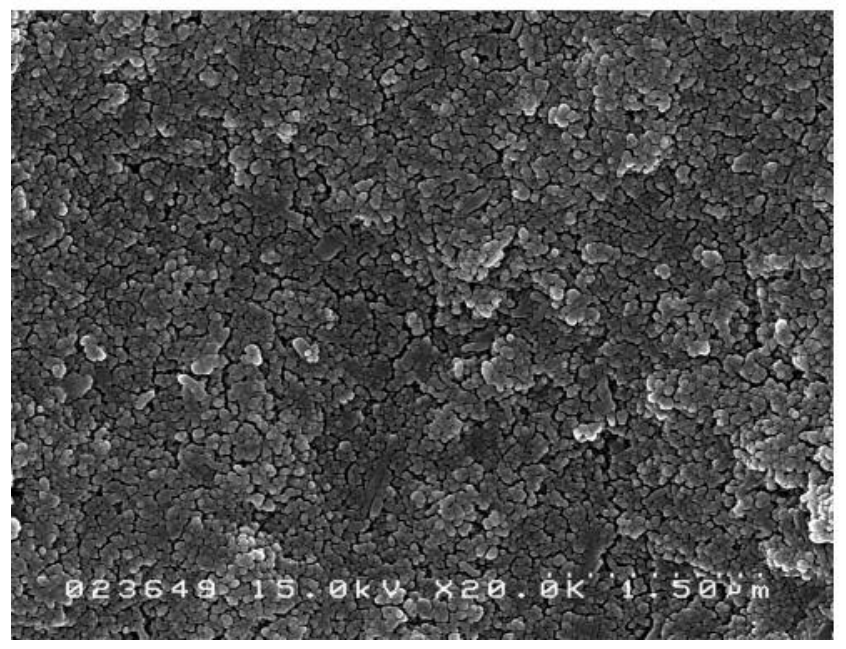

B

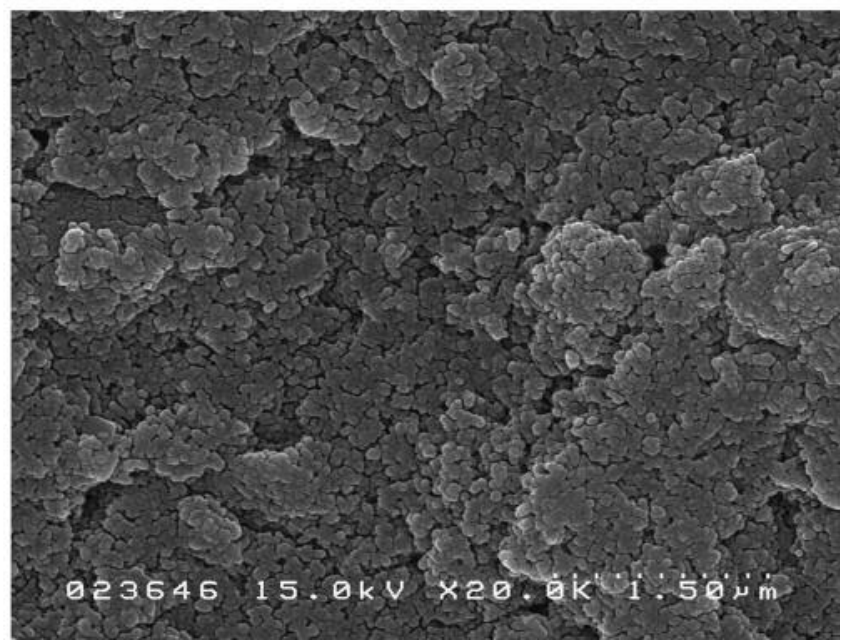

Figure 2. Scanning electron microscopic images of the nano-hydroxyapatite gel implants. (×20,000). A: High-viscosity gel. B: Low-viscosity gel.

The cranial portion of the graft expanded after injection until week 4; when the graft was punctured, an almost transparent exudate flowed out. None of the mice showed clinical symptoms, such as gel-related dehiscence or infection, during the 12 weeks of follow-up. Furthermore, none of the mice died during the study period.

Micro-CT analysis. Representative examples of micro-CT images obtained at each time point are shown in Figure 4. Both types of graft material gradually decreased in volume and were replaced by regenerated bone. Furthermore, the low-viscosity implant gel was found to contain solid and liquid components; however, the cavity region was thought to contain the liquid portion, which eventually disappeared in all cases.

The bone augmentation volume and height achieved by each type of implant gel at $0,4,8$, and 12 weeks is shown in Figures 5 and 6. A higher volume was found at all time points in the specimens injected with the high-viscosity implant gel than in those injected with the low-viscosity gel. The increase in volume reached a peak at 4 weeks after surgery, with a gradual decrease in volume noted from 8 weeks onwards and a significant difference was observed between the groups at 8 and 12 weeks. Low-viscous implant gel resulted in a greater height than the high-viscous gel at all time points, being significantly so at 8 weeks.

Histological analysis. At 12 weeks after surgery, new bone formation in the bone augmentation region was detected in both gel implant groups (Figure 7). The graft material was visible in the new bone in both groups but was absorbed and substituted with bone to a greater extent in the group injected with the low-viscosity implant gel and in which many osteoblasts were visible. 


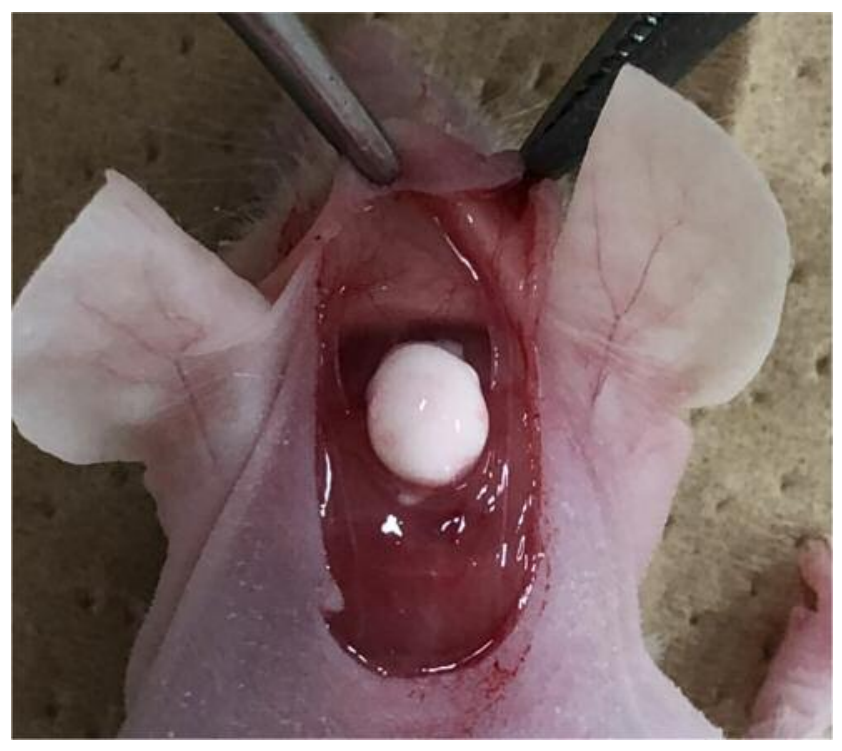

Figure 3. Photograph showing injection of $500 \mu$ l of nano-hydroxyapatite gel under the periosteum in the central portion of the mouse calvaria.

The ratios of residual graft material to new bone in the bone augmentation region are shown in Figures 8 and 9 . There was no significant difference in the area containing residual material between the high-viscosity and lowviscosity implant groups (21\% vs. $28 \%)$ but the new bone area was significantly greater in the low-viscosity group than in the high-viscosity group ( $35 \%$ vs. $26 \%$ ).

\section{Discussion}

Sintered HA has been established as a biocompatible and osteoconductive bone filler (30-33). However, it is poorly absorbed and remains in the body for the rest of the patient' $\mathrm{s}$ life, and there is an ever-present risk of secondary infection. Degradation of HA in vivo occurs by aqueous dissolution in body fluids, resorption by osteoclasts and multinuclear cells, and phagocytosis by macrophages. The degradation process is slow, but absorbent materials that can be replaced with autologous bone have recently been developed (16-18). HA nanoparticles can now be used to repair a bone defect because they are resorbed more rapidly, and the new bone tissue formed is a biocomposite of organic collagen and inorganic HA nanoparticles (27-29). More bioactivity is achieved by use of HA nanoparticles in synthetic grafts with crystals resembling natural bone than by use of larger HA particles. HA nanoparticles also have a positive effect on protein adhesion, cell adhesion, and proliferation $(34,35)$. Recent studies suggest that nanocrystalline HA powders have improved sinterability and densification as a result of their greater surface area (36). However, these powders are

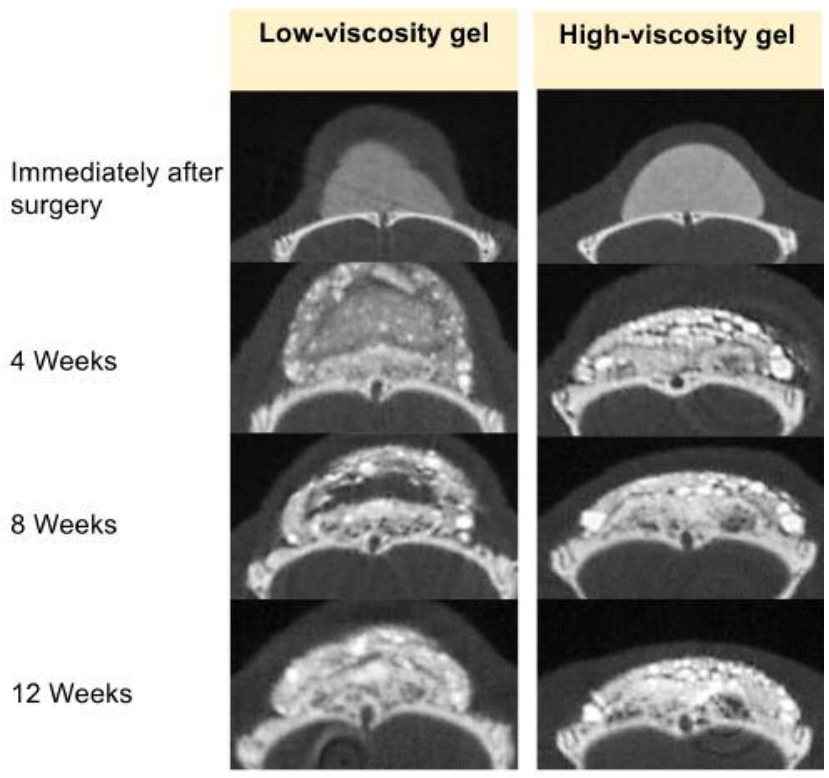

Figure 4. Micro-computed tomographic images showing bone augmentation at different time points.

difficult to shape into the specific form required for bone repair and implantation because of their intrinsic hardness, fragility, and lack of flexibility. We used glycerin and sodium carboxymethylcellulose as the gel carrier for injection in this study. This is the same matrix as that found in Radiesse paste, which is already used for regeneration of soft tissue and has a confirmed safety profile (37). There are several reports on the use of nanocrystalline HA powders for bone regeneration (27-29). Conventional vertical augmentation of bone normally consists of guided bone regeneration using an onlay bone graft. These methods involve surgical procedures with a high risk of complications and failure (38). Therefore, a bioactive injectable scaffold might be an attractive alternative that can prevent the need for invasive ridge augmentation surgery.

A variety of composite scaffolds have been used to remodel bone, including bone morphogenetic protein (28) and HA nanoparticles in mesenchymal stem cells (27). Hatakeyama et al. (29) used a nano-HA-collagen complex in the rat cranium and found that nano-HA degraded by releasing a small amount of calcium and phosphate ions and had the ability to form new bone with angiogenesis. However, to our knowledge, there have been no reports on the usefulness in bone regeneration using bone substitutes composed only of HA nanoparticles. Therefore, we aimed to evaluate the usefulness of gel-like bone substitutes containing HA nanoparticles for bone augmentation in vivo.

Our radiological analysis showed that the greatest increase in bone volume occurred in week 4 after surgery, regardless of the viscosity of the graft material, and 

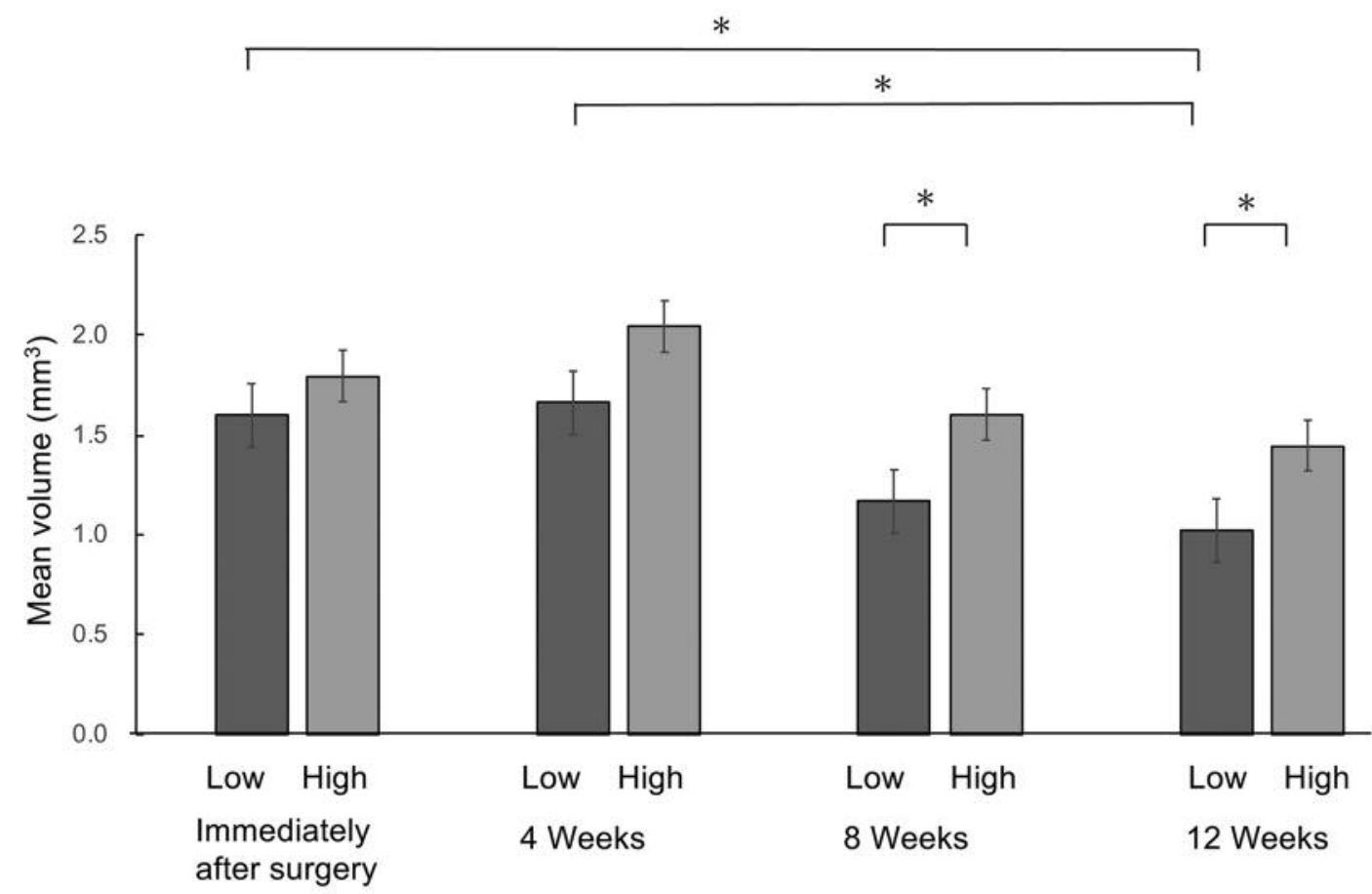

Figure 5. Mean volume of bone augmentation area at 0,4,8, and 12 weeks after injection of each type of nano-hydroxyapatite gel. The error bars indicate standard deviation. *Significantly different at $p<0.05$.

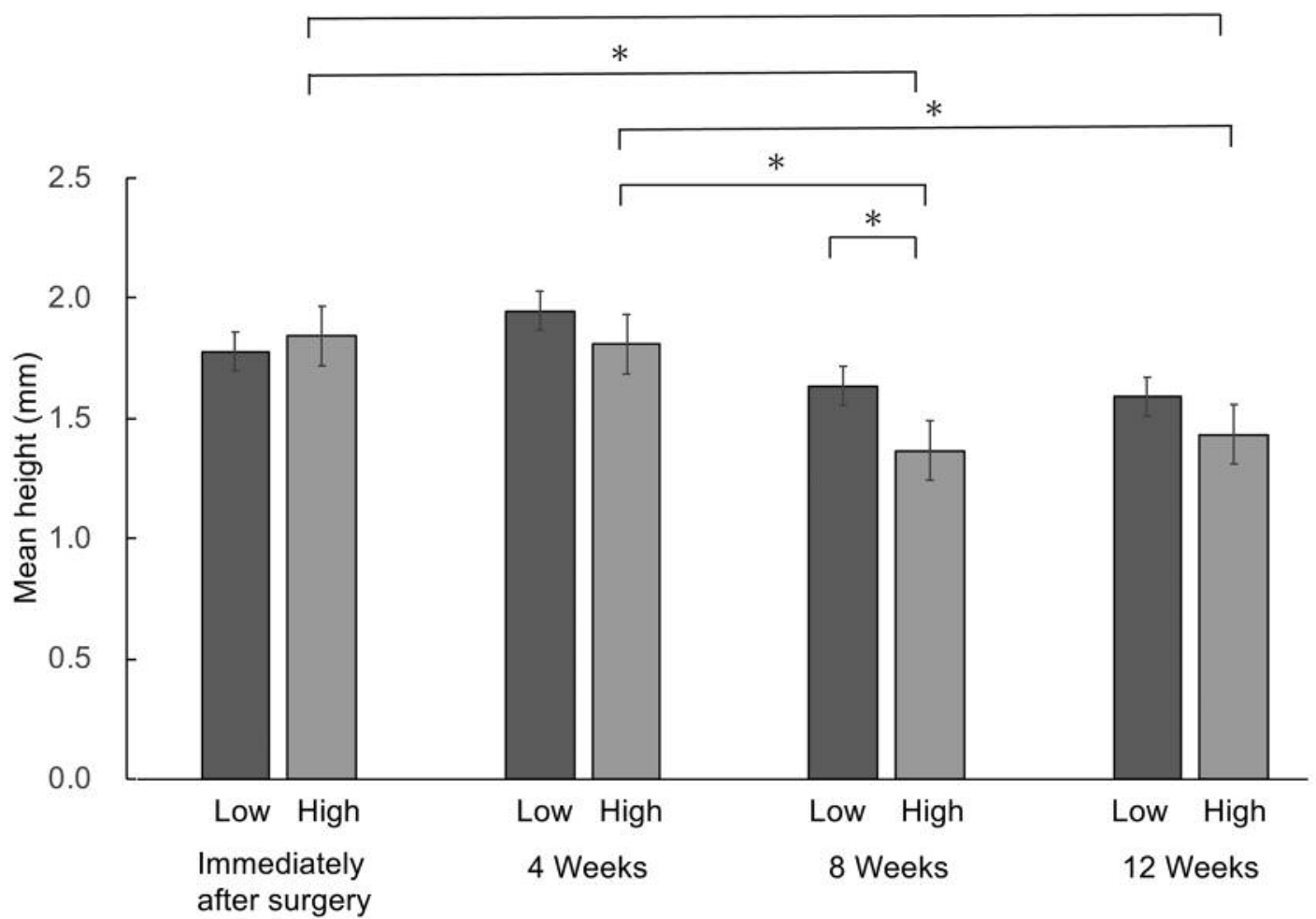

Figure 6. Mean maximum height of bone augmentation at 0,4,8, and 12 weeks after injection of each type of nano-hydroxyapatite gel. The error bars indicate standard deviation. *Significantly different at $p<0.05$. 
A

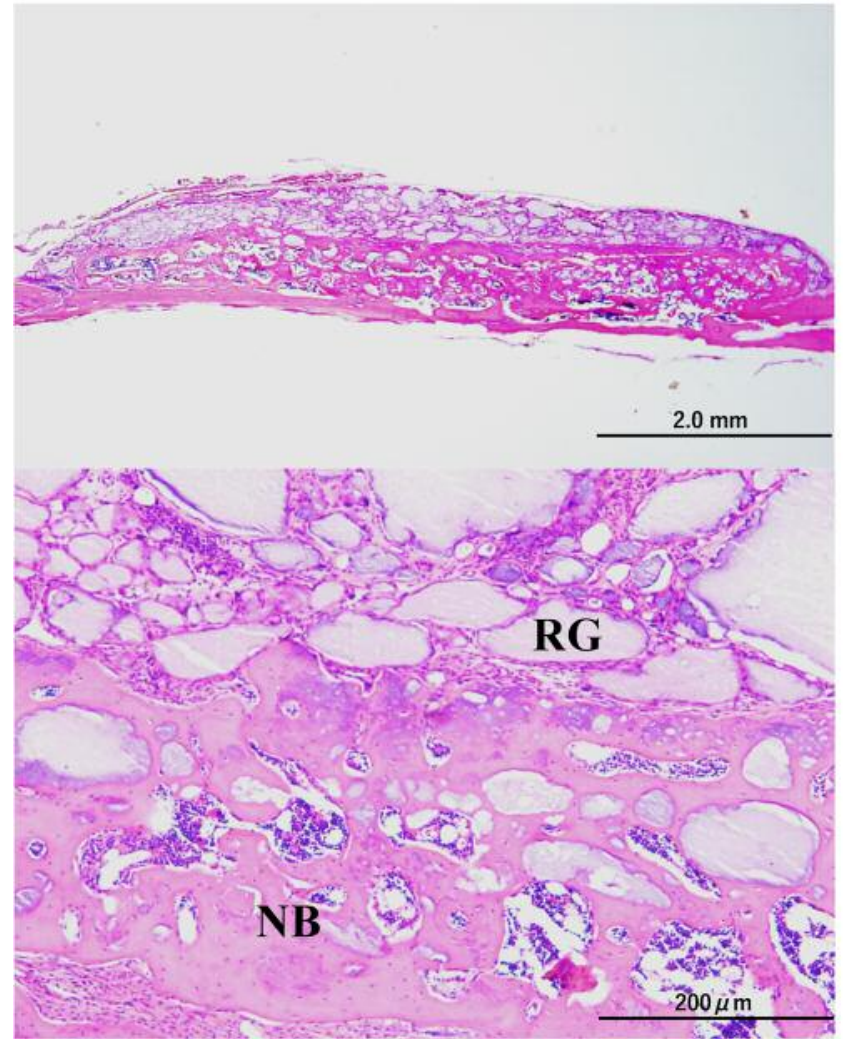

B
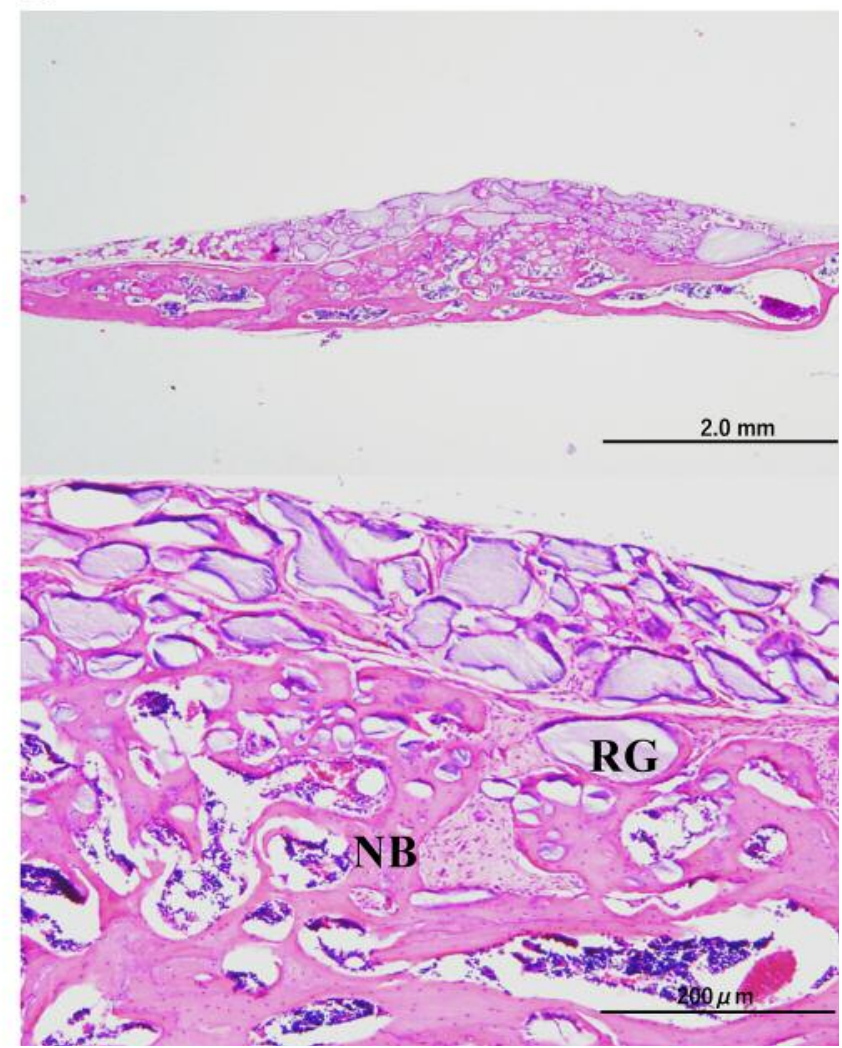

Figure 7. Histological images of hematoxylin and eosin-stained bone tissue 12 weeks after implantation of low-viscosity (A) and high-viscosity (B) gels at low magnification (upper panel) and high magnification (lower panel). RG: Residual graft materials; NB: new bone.

gradually decreased thereafter. This pattern of change in volume might reflect the initial absorbance of water from the surrounding tissues and its subsequent disappearance with expansion of the graft material component. However, a more detailed evaluation will be necessary. The bone augmentation volume was greater in the high-viscosity implant group than in the low-viscosity implant group at all time points, although the difference was statistically significant only at 8 and 12 weeks. It is likely that the decrease in the rate of expansion of bone volume from week 4 postoperatively onwards was due to the transplanted material being replaced with new bone and absorbed over time. On the other hand, maximum bone augmentation height in CT image indicated a pattern that was reverse to that for volume. The high-viscosity implant gel tended to expand horizontally, whereas the low-viscosity implant gel was augmented vertically. It was thought that liquid components of the low-viscosity implant gel which had separated by the fourth week influenced augmentation vertically. Because the high-viscosity gel maintained its condition without water separating, it was speculated that when the gel was pressed against the skull it expanded.
Histological evaluation at 12 weeks indicated that the new bone area was significantly greater in the low-viscosity implant group than in the high-viscosity implant group (35\% vs. 26\%). There was no significant difference in the area of the graft material between the high- and lowviscosity implant groups (13\% vs. $12 \%)$. We believe that more new bone volume was achieved in the augmentation region in the group that received the low-viscosity implant gel because this gel was substituted for bone more rapidly and resulted in more rapid bone remodeling. The lowviscosity implant gel contained less HA, which would have resulted in an increased volume of water at the bone regeneration site. Therefore, the low-viscosity gel would have dispersed more readily, with increased infiltration of the cell component and earlier remodeling of bone, leading to increased formation of new bone. Currently available injectable nano-HA gel materials may be effective for bone augmentation and might potentially reduce surgical complexity, likelihood of exposure of graft material, and risk of infection. In this study, bone augmentation was achieved with a minimally invasive procedure using a single subperiosteal injection of nano-HA gel without the need for 


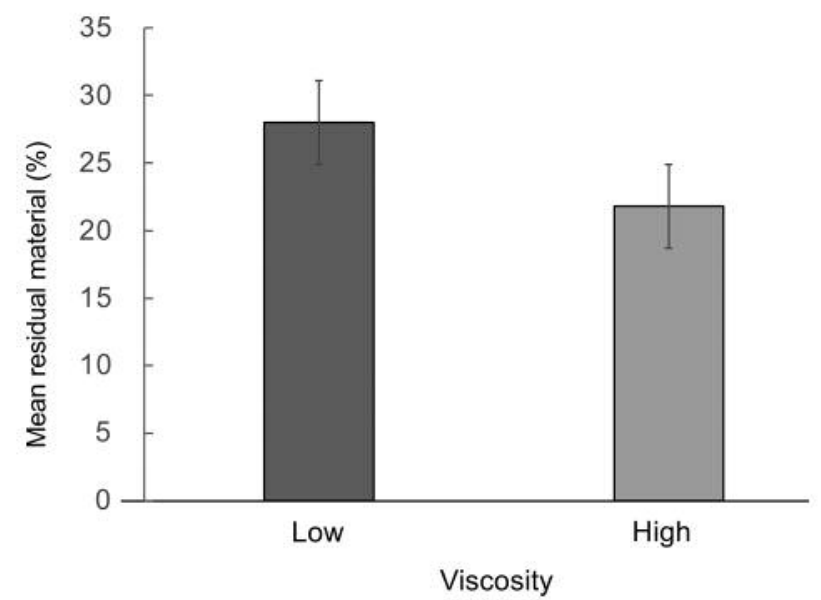

Figure 8. Mean residual material occupancy rate for augmented portion of bone. The error bars indicate standard deviation. *Significantly different at $p<0.05$.

further administration of stem cells or growth factors. However, given that this experiment was conducted over a relatively short period of 12 weeks, longer-term evaluation will be needed. Additional studies that include the use of nano-HA gel at other anatomical sites in other species will also be required.

Our findings indicate that gelatinous graft materials containing HA nanoparticles are useful for vertical bone augmentation. Greater bone augmentation was achieved using the high-viscosity gel compared with the low-viscosity gel; however, new bone area was significantly greater with the low-viscosity gel. Injection of nano-HA gel is a minimally invasive procedure with potential utility in bone augmentation.

\section{Conflicts of Interest}

This study was partly supported by Okabe Co., Ltd. The Authors declare no other potential conflicts of interest with respect to the research, authorship, or publication of this article.

\section{Authors' Contributions}

EM conceived and designed the experiments, AK and EM performed the experiments, AK and EM analyzed the data; $\mathrm{AK}$ and EM wrote the article. HH critically reviewed the article. All Authors approved the final version of the article, and agree to be accountable for all aspects of the work in ensuring that questions related to the accuracy or integrity of any part of the work are appropriately investigated and resolved.

\section{Acknowledgements}

The Authors are grateful to Mr. Kogai Yasumichi of SofSera Corporation for his advice and encouragement.

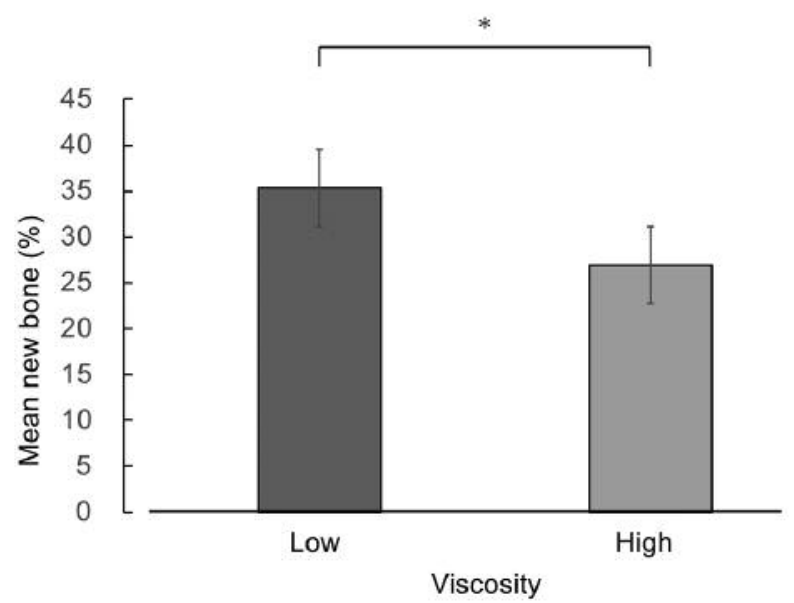

Figure 9. Mean new bone occupancy rate for augmented areas of bone. The error bars indicate standard deviation. No significant difference was assumed.

\section{References}

1 de Sousa CA, Lemos CAA, Santiago JF Jùnior, Faverani LP and Pellizzer EP: Bone augmentation using autogenous bone versus biomaterial in the posterior region of atrophic mandibles. A sustematic review and meta-analysis. J Dent 76: 1-8, 2018. PMID: 29959062. DOI: 10.1016/j.jdent.2018.06.014

2 Troiano G, Zhurakivs.ka K, Lo Muzio L, Laino L, Cicciù M and Lo Russo L: Combination of bone graft and resorbable membrane for alveolar ridge preservation: A systematic review, meta-analysis and trial sequential analysis. J Periodontol 12: 1-17, 2017. PMID: 28895779. DOI: 10.1902/ jop.2017.170241

3 De Risi V, Clementini M, Vittorini G, Mannocci A and De Sanctis M: Alveolar ridge preservation techniques: a systematic review and meta-analysis of histological and histomorphometrical deta. Clin Oral Implants Res 26: 50-68, 2015. PMID: 27007188. DOI: $10.1111 / \mathrm{clr} .12288$

4 Fretwurst T, Spanou A, Nelson K, Wein M, Steinberg T and Stricker A: Comparison of four different allogeneic bone grafts for alveolar ridge reconstruction: a preliminary histologic and biochemical analysis. Oral Surg Oral Med Oral Pathol Oral Radiol 118: 424-431, 2014. PMID: 25183228. DOI: 10.1016/j.oooo.2014.05.020

5 Merli M, Moscatelli M, Mariotti G, Pagliaro U, Raffaelli E and Nieri M: Comparing membranes and bone substitutes in a onestage procedure for horizontal bone augmentation. A doubleblind randomised controlled trial. Eur J Oral Implantol 8: 271281, 2015. PMID: 26355171.

6 Kent J N, Quinn J H, Zide M F, Guerra LR and Boyne PJ: Alveolar ridge augmentation using nonresorbable hydroxylapatite with or without autogenous cancellous bone. J Oral Maxillofac Surg 41: 629-942, 1983. PMID: 6312003. DOI: 10.1016/0278-2391(83)90016-2

7 Alling CC: Hydroxyapatite augmentation of edentulous ridges. J Prosthet Dent 52: 825-831, 1984. PMID: 6392514. DOI: 10.1016/s0022-3913(84)80013-x 
8 Krejci C B, Bissada N F, Farah C and Greenwell H: Clinical evaluation of porous and nonporous hydroxyapatite in the treatment of human periodontal bony defects. J Periodontol 58: 521-528, 1987. PMID: 3040959. DOI: 10.1902/jop.1987.58.8.521

9 Moreira-Gonzalez A, Jackson IT, Miyawaki T, DiNick V and Yavuzer R: Augmentation of the craniomaxillofacial region using porous hydroxyapatite granules. Plast Reconstr Surg 111: 1808-1817, 2003. PMID: 12711940. DOI: 10.1097/01.PRS. 0000055432.20074 .93

10 Mangano C, Scarano A, Iezzi G, Orsini G, Perrotti V, Mangano F, Montini S, Piccirilli $M$ and Piattelli: A Maxillary sinus augmentation using an engineered porous hydroxyapatite: A clinical, histological, and transmission electron microscopy study in man. J Oral Implantol 32: 122-131, 2006. PMID: 16836176. DOI: $10.1563 / 796.1$

11 Mangano C, Bartolucci EG and Mazzocco C: A new porous hydroxyapatite for promotion of bone regeneration in maxillary sinus augmentation: Clinical and histologic study in humans. Int J Oral Maxillofac Implants 18: 23-30, 2003. PMID: 12608665.

12 von Wowern $\mathrm{N}$ and Worsaae $\mathrm{N}$ : Changes in mandibular mineral content 3 years after residual ridge augmentation with porous hydroxyapatite: A clinical report. J Oral Maxillofac Implants 8 : 681-687, 1993. PMID: 8181831.

13 Heinz B, Kasaj A, Teich M and Jepsen S: Clinical effects of nanocrystalline hydroxyapatite paste in the treatment of intrabony periodontal defects: A randomized controlled clinical study. Clin Oral Investig 14: 525-531, 2010. PMID: 19680697. DOI: $10.1007 / \mathrm{s} 00784-009-0325-\mathrm{x}$

14 Ding Z, Han H, Fan Z, Lu H, Sang Y, Yao Y, Cheng Q, Lu Q and Kaplan DL: Nanoscale silk-hydroxyapatite hydrogels for injectable bone biomaterials. ACS Appl Mater Interfaces 9: 16913-16921, 2017. PMID: 28471165. DOI: 10.1021/acsami. $7 \mathrm{~b} 03932$

15 Cardoso DA, van den Beucken JJ, Both LL, Bender J, Jansen JA and Leeuwenburgh SC: Gelation and biocompatibility of injectable alginate-calcium phosphate gels for bone regeneration. J Biomed Mater Res A 102: 808-817, 2014. PMID: 23589413. DOI: $10.1002 / \mathrm{jbm} . a .347541$

16 Yamazaki N, Hirano M, Nanno K, Sugiyasu K, Tamai N, Hashimoto N, Yoshikawa $\mathrm{H}$ and Myoui A: A comparative assessment of synthetic ceramic bone substitutes with different composition and microstructure in rabbit femoral condyle model. J Biomed Mater Res B Appl Biomater 91: 788-798, 2009. PMID: 19572298. DOI: 10.1002/jbm.b.31457

17 Tsuchiya A, Sotome S, Asou Y, Kikuchi M, Koyama Y, Ogawa $\mathrm{T}$, Tanaka $\mathbf{J}$ and Shinomiya K: Effects of pore size and implant volume of porous hydroxyapatite/collagen $(\mathrm{HAp} / \mathrm{Col})$ on bone formation in a rabbit bone defect model. J Med Dent Sci 55: 9199, 2008. PMID: 19845154.

18 Sotome S, Ae K, Okawa A, Ishizuki M, Morioka H, Matsumoto S, Nakamura T, Abe S, Beppu Y and Shinomiya K: Efficacy and safety of porous hydoroxyapatite/type 1 collagen composite implantation for bone regeneration: A randomized controlled study. J Orthop Sci 21: 373-380, 2016. PMID: 26961287. DOI: 10.1016/j.jos.2016.01.007

19 Karageorgiou V and Kaplan D: Porosity of 3D biomaterial scaffolds and osteogenesis. Biomaterials 26: 5474-5491, 2005. PMID: 15860204. DOI: 10.1016/j.biomaterials.2005.02.002

20 van Eeden SP and Ripamonti U: Bone differentiation in porous hydroxyapatite in baboons is regulated by the geometry of the substratum: Implications for reconstructive craniofacial surgery. Plast Reconstr Surg 93: 959-969, 1994. PMID: 8134489. DOI: 10.1097/00006534-199404001-00010

21 Chhetri DK, Jahan-Parwar B, Hart SD, Bhuta SM and Berke GS: Injection laryngoplasty with calcium hydroxylapatite gel implant in an in vivo canine model. Ann Otol Rhinol Laryngol 113: 259264, 2004. PMID: 15112967. DOI: 10.1177/000348940411300402

22 Rosen CA, Gartner-Schmidt J, Casiano R, Anderson TD, Johnson F, Remacle M, Sataloff RT, Abitbol J, Shaw G, Archer $S$ and Zraick RI: Vocal fold augmentation with calcium hydroxylapatite: Twelve-month report. Laryngoscope 119: 10331041, 2009. PMID: 19274731. DOI: 10.1002/lary.20126

23 DeFatta RA, Chowdhury FR and Sataloff RT: Complications of injection laryngoplasty using calcium hydroxylapatite. J Voice 26: 614-618, 2012. PMID: 22056892. DOI: 10.1016/j.jvoice. 2011.08.005

24 Cantillo-Baños E, Jurado-Ramos A, Gutiérrez-Jódas J and ArizaVargas L: Vocal fold insufficiency: Medialization laryngoplasty $v s$. calcium hydroxylapatite (Rasiesse Voice ${ }^{\circledR}$ ). Acta OtoLaryngologica 133: 270-275, 2013. PMID: 23145984. DOI: 10.3109/00016489.2012.728717

25 Watari F, Takashi N, Yokoyama A, Uo M, Akasaka T, Sato Y, Abe S, Totsuka Y and Tohiji K: Material nanosizing effect on living organisms: Non-specific, biointeractive, physical size effects. I R Soc Interface 6: S371-388, 2009. PMID: 19364724. DOI: 10.1098/rsif.2008.0488.focus

26 Iwamoto T, Terada T, Kogai Y, Okada M, Fujii S and Furuzono $\mathrm{T}$ : Development of microspheres covered with hydroxyapatite nanocrystals as cell scaffold for angiogenesis. Functional Mater Lett 5: 614-616, 2012. DOI: 10.1142/S1793604712600107

27 Xue D, Zheng Q and Zong C: Osteochondral repair using porous poly(lactide-co-glycolide)/nano-hydroxyapatite hybrid scaffolds with undifferentiated mesenchymal stem cells in a rat model. J Biomed Mater Res A 94: 259-270, 2010. PMID: 20166224. DOI: 10.1002/jbm.a.32691

$28 \mathrm{Li}$ J, Hong $\mathrm{J}$ and Zheng Q: Repair of rat cranial bone defects with nHAC/PLLA and BMP-2-related peptide or rhBMP-2. J Orthop Res 29: 1745-1752, 2011. PMID: 21500252. DOI: 10.1002/jor.21439

29 Hatakeyama W, Taira M, Takefuji K, Kihara H and Kondo H: Bone-regeneration Trial of rat critical-size calvarial defects using nano-apatite/collagen composites. Nano Biomedicine 5: 95-103, 2013. DOI: $10.11344 /$ nano.5.95

30 Denissen HW and de Groot K: Immediate dental root implants from synthetic dense calcium hydroxylapatite. J Prosthet Dent 42: 551-556, 1979. PMID: 290806. DOI: 10.1016/00223913(79)90253-1

31 LeGeros RZ: Properties of osteoconductive biomaterials: Calcium phosphates. Clin Orthop 395: 81-98, 2002. PMID: 11937868. DOI: $10.1097 / 00003086-200202000-00009$

32 Bucholz RW: Nonallograft osteoconductive bone graft substitutes. Clin Orthop 395: 44-52, 2002. PMID: 11937865. DOI: $10.1097 / 00003086-200202000-00006$

33 Giannoudis RV, Dinopoulos H and Tsiridis E: Bone substitutes: An update. Injury Int J Care Injured 36S: S20-S27, 2005. PMID: 16188545. DOI: $10.1016 /$ j.injury.2005.07.029

34 Garagiola U, Grigolato R, Soldo R, Bacchini M, Bassi G, Roncucci R and De Nardi S: Computer-aided design/computeraided manufacturing of hydroxyapatite scaffolds for bone reconstruction in jawbone atrophy: A systematic review and case 
report. Maxillofac Plast Reconstr Surg 38: 2, 2016. PMID: 26767187. DOI: $10.1186 / \mathrm{s} 40902-015-0048-7$

35 Teotia, A.K., Raina, D.B., Singh, C, Sinha N, Isaksson H, Tägil M, Lidgren L and Kumar A: Nano-hydroxyapatite bone substitute functionalized with bone active molecules for enhanced cranial bone regeneration. ACS Appl Mater Interfaces 9: 6818-6828, 2017. PMID: 28171719. DOI: 10.1021/acsami. $6 \mathrm{~b} 14782$

36 Legeros RZ: Biodegradation and bioresorption of calcium phosphate ceramics. Clin Mater 14: 65-88, 1993. PMID: 10171998. DOI: 10.1016/0267-6605(93)90049-d

37 de Almeida AT, Figueredo V, da Cunha ALG, Casabona G, Costa de Faria JR, Alves EV, Sato M, Branco A, Guarnieri C and Palermo $\mathrm{E}$ : Consensus recommendations for the use of hyperdiluted calcium hydroxyapatite (Radiesse) as a face and body biostimulatory agent. Plastic Reconstr Surg Global Open 7(3): e2160, 2019. PMID: 31044123. DOI: $10.1097 /$ GOX.0000000000002160

$38 \mathrm{Li} \mathrm{J}$ and Wang HL: Common implant-related advanced bone grafting complications: classification, etiology, and management. Implant Dentistry 17: 389-401, 2008. PMID: 19077576. DOI: 10.1097/ID.0b013e31818c4992

Received December 31, 2019

Revised January 21, 2020

Accepted January 24, 2020 